\title{
Muscle Impairment in Neuromuscular Disease Using an Expiratory/Inspiratory Pressure Ratio
}

\author{
Guilherme Fregonezi PT PhD, Ingrid G Azevedo PT, Vanessa R Resqueti PT PhD, \\ Armèle D De Andrade PT PhD, Lucien P Gualdi PT PhD, Andrea Aliverti PhD, \\ Mário ET Dourado-Junior MD MSc, and Verônica F Parreira PT PhD
}

\begin{abstract}
BACKGROUND: Neuromuscular diseases (NMDs) lead to different weakness patterns, and most patients with NMDs develop respiratory failure. Inspiratory and expiratory muscle strength can be measured by maximum static inspiratory pressure $\left(\mathbf{P}_{\text {Imax }}\right)$ and maximum static expiratory pressure $\left(\mathbf{P}_{\text {Emax }}\right)$, and the relationship between them has not been well described in healthy subjects and subjects with NMDs. Our aim was to assess expiratory/inspiratory muscle strength in NMDs and healthy subjects and calculate $\mathbf{P}_{\text {Emax }} / \mathbf{P}_{\text {Imax }}$ ratio for these groups. METHODS: Seventy (35 males) subjects with NMDs (amyotrophic lateral sclerosis, myasthenia gravis, and myotonic dystrophy), and 93 (47 males) healthy individuals 20-80 $y$ of age were evaluated for anthropometry, pulmonary function, $P_{\text {Imax }}$, and $\mathbf{P}_{\text {Emax }}$, respectively. RESULTS: Healthy individuals showed greater values for $\mathbf{P}_{\operatorname{Imax}}$ and $\mathbf{P}_{\text {Emax }}$ when compared with subjects with NMDs. $P_{\text {Emax }} / P_{\text {Imax }}$ ratio for healthy subjects was $1.31 \pm 0.26$, and $P_{\text {Emax }} \% / P_{\text {Imax }} \%$ was $1.04 \pm 0.05$; for subjects with $N M D s, P_{E m a x} / P_{\text {Imax }}$ ratio was $1.45 \pm 0.65$, and $\mathbf{P}_{\text {Emax }} \% / \mathbf{P}_{\text {Imax }} \%$ ratio was $1.42 \pm 0.67$. We found that $\mathbf{P}_{E \max } \% / \mathbf{P}_{\text {Imax }} \%$ for myotonic dystrophy was $0.93 \pm 0.24$, for myasthenia gravis $1.94 \pm 0.6$, and for amyotrophic lateral sclerosis $1.33 \pm 0.62$ when we analyzed them separately. All healthy individuals showed higher $\mathbf{P}_{\text {Emax }}$ compared with $\mathbf{P}_{\text {Imax }}$. For subjects with NMDs, the impairment of $\mathbf{P}_{E \max }$ and $\mathbf{P}_{I \max }$ is different among the $\mathbf{3}$ pathologies studied $(P<.001)$. CONCLUSIONS: Healthy individuals and subjects with NMDs showed higher $P_{\text {Emax }}$ in comparison to $P_{\text {Imax }}$ regarding the $P_{E m a x} / P_{I m a x}$ ratio. Based on the ratio, it is possible to state that NMDs show different patterns of respiratory muscle strength loss. $\mathbf{P}_{E \max } / \mathbf{P}_{\mathrm{Imax}}$ ratio is a useful parameter to assess the impairment of respiratory muscles in a patient and to customize rehabilitation and treatment. Key words: respiratory muscle strength; respiratory muscle imbalance; neuromuscular diseases; respiratory therapy; $P_{\text {Emax }} / P_{\text {Imax }}$ ratio. [Respir Care 2015;60(4):533-539. (C) 2015 Daedalus Enterprises]
\end{abstract}

\section{Introduction}

Neuromuscular diseases (NMDs) such as amyotrophic lateral sclerosis (ALS), myasthenia gravis (MG), and myo-

Dr Fregonezi, Ms Azevedo, Dr Resqueti, and Dr Gualdi are affiliated with the Physical Therapy Department of Universidade Federal do Rio Grande do Norte, Natal, Brazil; Dr De Andrade is affiliated with the Physical Therapy Department of Universidade Federal de Pernambuco, Recife, Brazil; Dr Aliverti is affiliated with the Dipartimento di Elettronica, Informazione e Bioingegneria-Politecnico di Milano, Milan, Italy; Dr Dourado-Junior is affiliated with Hospital Universitário Onofre LopesUniversidade Federal do Rio Grande do Norte, Natal, Brazil; Dr Parreira is affiliated with the Physical Therapy Department of Universidade Federal de Minas Gerais, Belo Horizonte, Brazil.

Ms Azevedo presented a poster version of this paper at the 21st Annual Conference of the European Respiratory Society, held 24-28 September, 2011, in Amsterdam, Netherlands. tonic dystrophy (MD) show reductions of maximum static inspiratory pressure $\left(\mathrm{P}_{\operatorname{Imax}}\right)$ and maximum static expira-

\footnotetext{
This research was supported by Coordenação de Aperfeiçoamento de Pessoal de Nível Superior (CAPES) grant Programa Nacional de Cooperação Acadêmica (PROCAD) 764/2010 from Universidade Federal do Rio Grande do Norte/ Universidade Federal de Pernambuco/Universidade Federal de Minas Gerais, as well as a postdoctoral scholarship to Dr Fregonezi from CAPES. The authors have disclosed no other conflicts of interest.
}

Correspondence: Guilherme Fregonezi PT PhD, Laboratório de Desempenho PneumoCardioVascular e Músculos Respiratórios Departamento de Fisioterapia, Universidade Federal do Rio Grande do Norte Campus Universitário Lagoa Nova, Caixa Postal 1524 59072-970 Natal, RN, Brazil. E-mail: fregonezi@ufrnet.br.

DOI: $10.4187 /$ respcare. 03367 
tory pressure $\left(\mathrm{P}_{\text {Emax }}\right)$ as well as an imbalance of inspiratory versus expiratory muscles. NMDs lead to weakness of either inspiratory or expiratory muscles, or both, and in advanced stages, most patients with NMDs develop respiratory failure. ${ }^{1}$

Measurements of $\mathrm{P}_{\operatorname{Imax}}$ and $\mathrm{P}_{\mathrm{Emax}}$ at the mouth were proposed by Black and Hyatt ${ }^{2}$ in the late 60 s as a noninvasive and simple method to determine inspiratory and expiratory muscle strength. ${ }^{3}$ Nowadays, this technique is widely used for clinical assessment, and a great number of authors have reported data regarding patients affected by different neurologic diseases. ${ }^{4-6}$

Inspiratory and expiratory muscles are both essential not only to allow ventilation, but also to preserve upper airway patency by an efficient cough mechanism that needs both inspiratory and expiratory muscle strength. ${ }^{4}$ In patients with NMDs, the reduction of inspiratory and/or expiratory muscle strength is thus related to ineffective alveolar ventilation and difficult airway clearance, which lead to increased risk of developing atelectasis, pneumonia and chronic respiratory insufficiency. ${ }^{7-9}$

Therefore, the assessment of absolute and relative inspiratory and expiratory muscle impairment is of high clinical relevance. Veale et $\mathrm{al}^{6}$ found a significant difference between $\mathrm{P}_{\text {Imax }}$ and $\mathrm{P}_{\text {Emax }}$ values in subjects with NMDs, namely facio-scapulo humoral dystrophy, limb girdle dystrophy, spinal muscular atrophy, mitochondrial myopathy, and polymyositis.

It is well known that, in the clinical course of ALS, respiratory muscle dysfunction is present in both inspiratory and expiratory muscles and shows a fast progression, whereas, in MD and MG, the respiratory muscle weakness shows a slower clinical course. Nevertheless, the relationship between inspiratory and expiratory muscle strength in NMDs and healthy subjects is unclear ${ }^{10}$ or has, at least, not been established. Our aim was to assess expiratory/inspiratory muscle strength in NMDs and healthy subjects and to calculate $\mathrm{P}_{\text {Emax }} / \mathrm{P}_{\text {Imax }}$ ratios for all groups as well as to compare these values between study groups. Based on previous findings, we hypothesized that all subjects with NMDs would show respiratory weakness, but with different inspiratory/expiratory weakness patterns according to the disease's characteristics.

\section{Methods}

\section{Subjects}

Two samples were invited to participate in the study, subjects with neuromuscular disease and healthy individuals, as a control group. Both were recruited for the study from February 2008 to February 2010. All subjects were recruited during routine follow-up visits at the Onofre Lopes University Hospital (Natal, Rio Grande do Norte, Brazil).

\section{QUICK LOOK}

\section{Current knowledge}

Neuromuscular diseases lead to different weakness patterns, and many patients go on to develop respiratory failure. Inspiratory and expiratory muscle strength are commonly measured by maximum static inspiratory pressure $\left(\mathrm{P}_{\text {Imax }}\right)$ and maximum static expiratory pressure $\left(\mathrm{P}_{\mathrm{Emax}}\right)$.

\section{What this paper contributes to our knowledge}

Healthy individuals and subjects with neuromuscular diseases showed higher $\mathrm{P}_{\text {Emax }}$ in comparison to $\mathrm{P}_{\text {Imax }}$. Based on the $\mathrm{P}_{\text {Imax }} / \mathrm{P}_{\text {Emax }}$ it was possible to demonstrate that neuromuscular diseases show different patterns of respiratory muscle strength loss. $\mathrm{P}_{\text {Imax }} / \mathrm{P}_{\text {Emax }}$ was a useful parameter to assess the impairment of respiratory muscles and to customize rehabilitation and treatment.

The study was performed at PneumoCardioVascular and Respiratory Muscle Performance Laboratory, Physical Therapy Department/Universidade Federal do Rio Grande do Norte. We included subjects diagnosed by the same neurologist (METD), based on clinical history and clinical stability (ie, without any exacerbation and not hospitalized) for at least 6 months before data collection. Cardiac or respiratory alterations were considered criteria for exclusion. Healthy subjects were recruited in the academic community (students, professors, and professionals) by public announcements. Volunteers with a history of other respiratory or heart diseases or neurological conditions that could influence the results, as well as those using any medication, were excluded. All participants gave written consent, and the study was approved by the hospital ethics committee (protocol 151/07). All procedures were conducted in accordance with the ethical standards of the Helsinki declaration. ${ }^{11}$

\section{Study Design}

After the physiotherapist gave a brief explanation on the purposes of the study and the adopted protocol, individuals submitted to an interview, anthropometric evaluation, spirometry, and muscle strength testing. Weight and height were assessed by Welmy scale R-110 (Welmy, Santa Bárbara d'Oeste, Brazil) and body mass index (BMI) was successively calculated. Spirometry and respiratory muscle strength were assessed in all subjects at the same day by the same experienced technician, in a single session. A resting period of 3 min was given to the subject between 
the tests. Resting time was increased if necessary (eg, at subject's request). Spirometry and maximal inspiratory and expiratory pressure were performed with the subject in a seated position.

\section{Spirometry}

Technical procedure, acceptability, and reproducibility criteria, as well as standardizations for measures, were in accordance with the Brazilian Society of Tisiology and Pneumology. ${ }^{12}$ Subjects were instructed about the procedures to be performed during the spirometry assessment. The spirometer was calibrated before the test, using a 3-L syringe, according to ambient temperature conditions. Participants were positioned sitting on a chair with feet supported and trunk flexion of $90^{\circ}$, with hands on the thighs without additional support. A nose clip was used, and subjects were instructed to take 3 slow breaths at tidal volume level through the mouth. On the fourth breath, they were required to perform a maximal inspiration to total lung capacity. Then, immediately after positioning the spirometer in the mouth, through a tubular stiff paper mouthpiece, participants were instructed to conduct a full and fast expiration (FVC maneuver) under vigorous verbal encouragement by the examiner. For the implementation of the FVC maneuver, participants were instructed to place the mouthpiece between the teeth, on the tongue, and keep it firmly with the lips placed around it, to prevent air leakage. Furthermore, anterior trunk flexion was not allowed during the procedure. A minimum of 3 and a maximum of 8 tests were conducted, with a 1-min interval between them. A Datospir 120 spirometer (Sibelmed, Barcelona, Spain) was used to measure $\mathrm{FEV}_{1}$ and FVC. Three reproducible maneuvers were performed, and the best curve was considered for the study. Results were expressed in both absolute and as percent-of-predicted values. ${ }^{13}$

\section{Respiratory Muscle Strength}

Respiratory muscle strength was assessed based on maximal respiratory pressure $\left(\mathrm{P}_{\text {Imax }}\right.$ and $\left.\mathrm{P}_{\text {Emax }}\right)$ procedures as originally described by Black and Hyatt. ${ }^{2}$ Pressures were measured with the subjects in the same position adopted during spirometry, with the nostrils occluded with a nose clip and by using a paper mouthpiece. $\mathrm{P}_{\mathrm{Imax}}$ and $\mathrm{P}_{\text {Emax }}$ were measured using a MicroRPM digital manometer (Micro Medical, Rochester, United Kingdom), respectively, at residual volume and total lung capacity. A total of 5-8 maneuvers were performed until 2 maximal values were reproducible (in accordance with the reproducibility and acceptability criteria standardized by the Brazilian Society of Pneumology and Tisiology). ${ }^{12}$ We considered the greatest pressure value obtained, with variation less than $10 \%$ among the 3 highest maneuvers. $\mathrm{P}_{\mathrm{Imax}}$ and $\mathrm{P}_{\mathrm{Emax}}$ were expressed both in absolute and in percent-of-predicted values, using reference values obtained for the Brazilian population. ${ }^{14}$

\section{Statistical Analysis}

Participants were characterized using descriptive statistics, obtaining the means \pm SD of age and BMI. The Shapiro-Wilk test was used to verify data normally. Unpaired $t$ test was applied to compare subjects with NMDs and healthy subjects. $\mathrm{P}_{\mathrm{Emax}} / \mathrm{P}_{\mathrm{Imax}}$ ratio was established through a single linear regression in healthy individuals and subjects with NMDs. Spirometric variables and respiratory pressures between the subjects with 3 types of NMDs and healthy subjects were calculated by one-way analysis of variance with Bonferroni post hoc test. For statistical analysis, Prism 5 (GraphPad Software, San Diego, California) software was used. Significance level was set at $P<.05$ with 2 -tailed approach.

\section{Results}

\section{Baseline Characteristics}

The study included 70 subjects ( 35 males) with NMDs and 93 (47 males) healthy individuals $20-80 \mathrm{y}$ of age. Subjects with NMDs were diagnosed as follows: MD (36\%), 18-76 y of age; MG (39\%), 33-80 y of age; and ALS (26\%), 39-76 y of age. No subject was wheelchairdependent at the moment of respiratory variable collection; however, 7 subjects with ALS were receiving nocturnal noninvasive ventilation. Regarding BMI, healthy individuals and subjects with MD and ALS were considered to be optimal weight, whereas subjects with MG were classified as overweight according to World Health Organization standards. ${ }^{15}$

The subjects' anthropometric characteristics and spirometric data are presented in Table 1. Healthy individuals and subjects with NMDs were similar in gender and BMI, but age was significantly different $(P<.001)$. The 3 groups of subjects with NMDs were different in terms of gender, age, and BMI $(P<.001)$. FVC, FVC ( $\%$ predicted $), \mathrm{FEV}_{1}$, $\mathrm{FEV}_{1}$ (\% predicted), and $\mathrm{FEV}_{1} / \mathrm{FVC}$, were significantly different between healthy individuals and subjects with NMDs $(P<.001)$, as well as between the 3 groups of subjects with NMDs $(P<.001)$ (Table 1$)$.

\section{$\mathbf{P}_{\text {Emax }}$ and $\mathbf{P}_{\text {Imax }}$ Ratio in Healthy Individuals and in Neuromuscular Subjects}

Table 2 reports $\mathrm{P}_{\text {Emax }}$ (absolute and \% predicted), $\mathrm{P}_{\text {Imax }}$ (absolute and $\%$ predicted), $\mathrm{P}_{\text {Emax }} / \mathrm{P}_{\text {Imax }}$ ratio, and percent-of-predicted $\mathrm{P}_{\mathrm{Emax}} / \mathrm{P}_{\text {Imax }}$ ratio in all the considered groups. All parameters (both absolute values and ratios) 
Respiratory Muscle IMPairment in Neuromuscular Disease

Table 1. Demographic and Anthropometric Characteristics and Lung Function Values

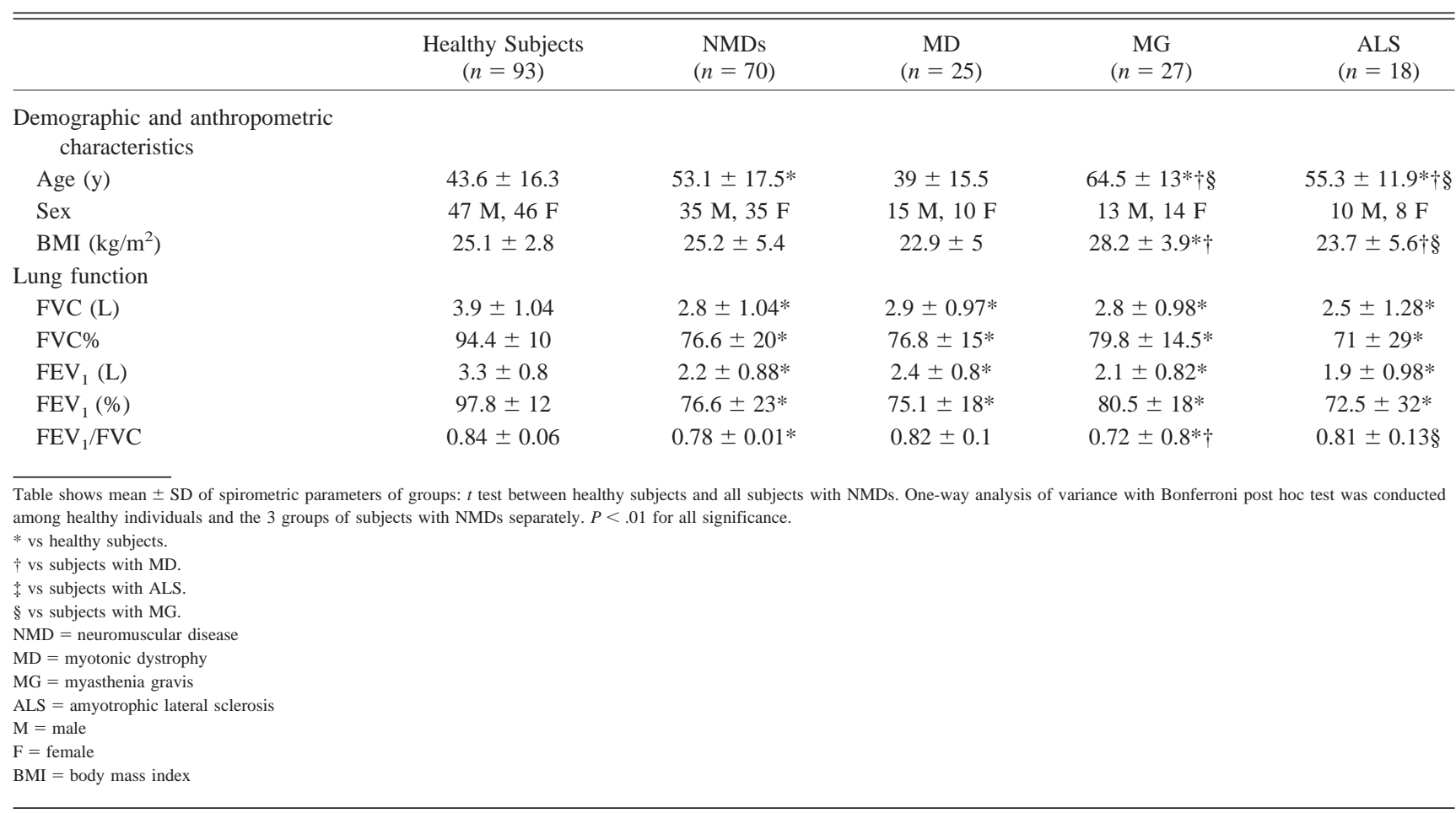

Table 2 Maximal Inspiratory Pressure, Maximal Expiratory Pressure, and Maximal Expiratory/Inspiratory Pressure Ratio Values for Healthy Individuals and Neuromuscular Subjects

\begin{tabular}{|c|c|c|c|c|c|}
\hline & $\begin{array}{l}\text { Healthy Subjects } \\
\quad(n=93)\end{array}$ & $\begin{array}{l}\text { NMDs } \\
(n=70)\end{array}$ & $\begin{array}{c}\text { MD } \\
(n=25)\end{array}$ & $\begin{array}{c}\text { MG } \\
(n=27)\end{array}$ & $\begin{array}{c}\text { ALS } \\
(n=18)\end{array}$ \\
\hline $\mathrm{P}_{\text {Emax }}\left(\mathrm{cm} \mathrm{H}_{2} \mathrm{O}\right)$ & $133 \pm 33$ & $83 \pm 38^{*}$ & $69 \pm 20^{*}$ & $109 \pm 37^{*}$ & $63 \pm 37 *$ \\
\hline $\mathrm{P}_{\text {Emax }}(\%$ pred $)$ & $122 \pm 21.3$ & $84.6 \pm 41.8^{*}$ & $62 \pm 21^{*}$ & $122.5 \pm 35 \dagger$ & $60 \pm 29 *+$ \\
\hline $\mathrm{P}_{\mathrm{Imax}}\left(\mathrm{cm} \mathrm{H} \mathrm{H}_{2} \mathrm{O}\right)$ & $102 \pm 26$ & $62 \pm 27^{*}$ & $75 \pm 30^{*}$ & $58.3 \pm 20 *$ & $50 \pm 26^{* \dagger} \dagger$ \\
\hline $\mathrm{P}_{\text {Imax }}(\%$ pred $)$ & $97 \pm 16.1$ & $63 \pm 23.2^{*}$ & $68.6 \pm 23.6^{*}$ & $65.5 \pm 18.1^{*}$ & $51 \pm 26.2^{*}$ \\
\hline $\mathrm{P}_{\text {Emax }} / \mathrm{P}_{\operatorname{Imax}}$ & $1.31 \pm 0.26$ & $1.45 \pm 0.65$ & $0.96 \pm 0.24 *$ & $1.96 \pm 0.56^{* \dagger}$ & $1.37 \pm 0.65 \dagger+$ \\
\hline $\mathrm{P}_{\text {Emax }} / \mathrm{P}_{\text {Imax }}(\%$ pred $)$ & $1.04 \pm 0.05$ & $1.42 \pm 0.67 *$ & $0.93 \pm 0.24 *$ & $1.94 \pm 0.60^{*} \dagger$ & $1.33 \pm 0.62 * \dagger+$ \\
\hline $\begin{array}{l}\text { Values are mean } \pm \text { SD of respiratory } \\
\text { conducted among healthy individuals } \\
* \text { vs healthy subjects. } \\
\dagger \text { vs subjects with MD. } \\
\text { ‡ vs subjects with MG. } \\
\mathrm{P}_{\text {Emax }} \text { = maximal expiratory pressure } \\
\% \text { pred = percent of predicted } \\
\mathrm{P}_{\text {Imax }}=\text { maximal inspiratory pressure } \\
\mathrm{NMD}=\text { neuromuscular disease } \\
\mathrm{MD}=\text { myotonic dystrophy } \\
\mathrm{MG}=\text { myasthenia gravis } \\
\mathrm{ALS}=\text { amyotrophic lateral sclerosis }\end{array}$ & $\begin{array}{l}\text { cular strength, determin } \\
\text { the } 3 \text { groups of NMDs }\end{array}$ & tween healthy subj & ubjects with NMD & lysis of variance & i post hoc test was \\
\hline
\end{tabular}

were significantly different between healthy subjects and subjects with NMDs. $\mathrm{P}_{\text {Emax }} / \mathrm{P}_{\text {Imax }}$ ratios were different in the different NMD groups.

Individual values of $\mathrm{P}_{\mathrm{Emax}} / \mathrm{P}_{\text {Imax }}$, both absolute and percent-of-predicted values, are shown in Figure 1. In healthy subjects, $\mathrm{P}_{\text {Emax }} / \mathrm{P}_{\text {Imax }}$ (ratio between absolute values) was, on average, greater than 1 . In subjects with MD and MG, this ratio was lower and higher than for healthy subjects, respectively. In subjects with ALS, although the average value was similar to healthy subjects, the variability was extremely large. When considering $\mathrm{P}_{\text {Emax }} / \mathrm{P}_{\mathrm{Imax}}$ (ratio between predicted values), this was, as expected, on average very close to 1 in healthy subjects with a very low spread. In the 3 considered NMDs, the variability of this 

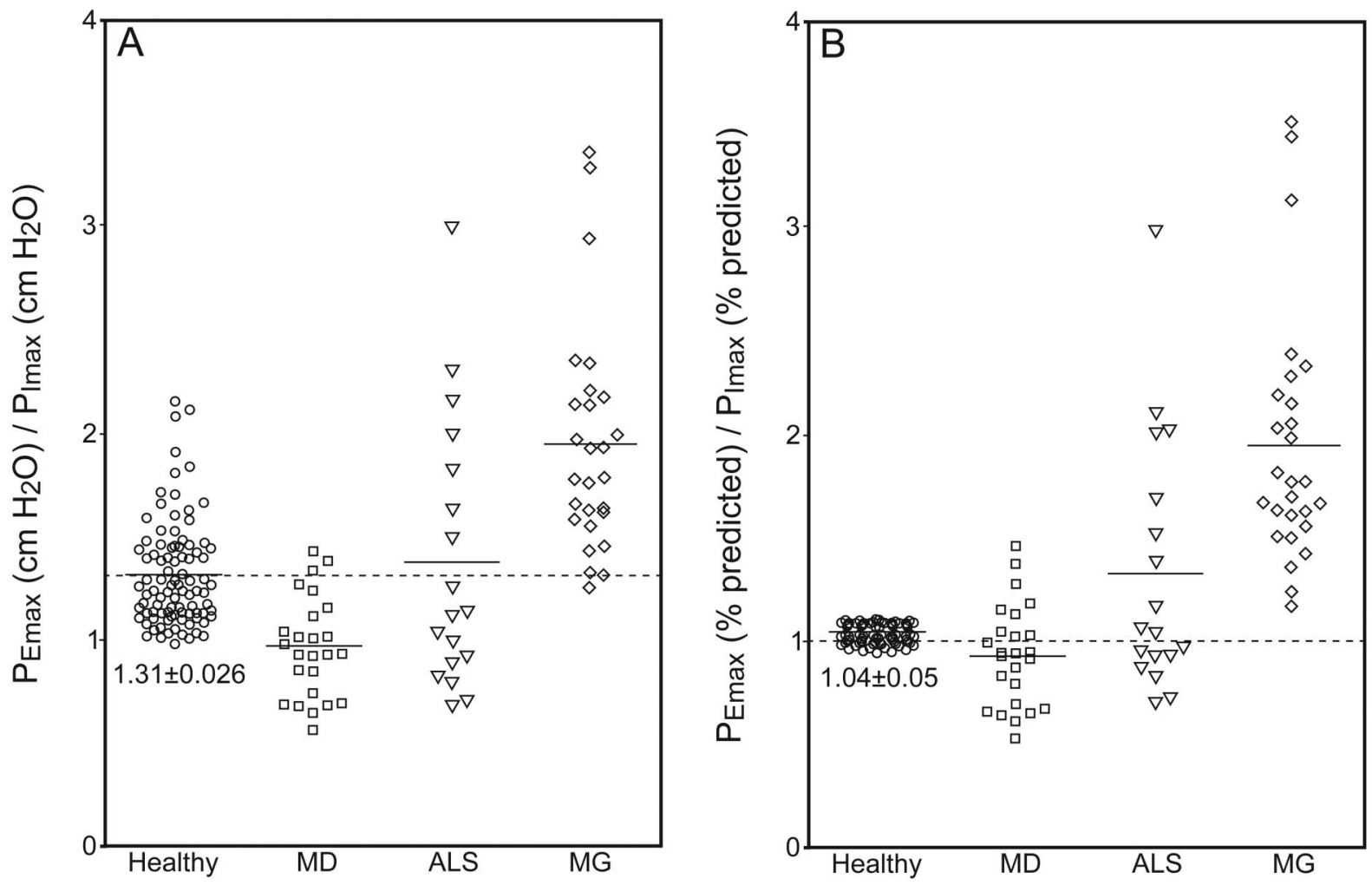

Fig. 1. $P_{E \max } / P_{\operatorname{Imax}}$ ratio for healthy individuals and subjects with NMDs. The distribution of absolute (A) and percent-of-predicted (B) values for each pathology is shown. ALS = amyotrophic lateral sclerosis; $M G=$ myasthenia gravis; $M D=$ myotonic dystrophy; $P_{E \max }=$ maximum static expiratory pressure; $\mathrm{P}_{\mathrm{Imax}}=$ maximum static inspiratory pressure. Analysis of variance with Bonferroni post hoc test was applied to identify differences among healthy subjects in relation to each group of NMD. $P<.001$ was considered significant. Dotted horizontal lines represent the overall mean; solid horizontal lines denote the mean for each group.

ratio was generally high and tended to increase passing from MD to ALS to MG.

As shown in Figure 2 (upper left panel), all healthy individuals were above the identity line $\left(\mathrm{P}_{\mathrm{Emax}}=\mathrm{P}_{\mathrm{Imax}}\right)$, showing higher $\mathrm{P}_{\text {Emax }}$ compared with $\mathrm{P}_{\text {Imax }}$. Conversely, a significant number of subjects with NMDs were below the dotted line, meaning that the impairment of $\mathrm{P}_{\mathrm{Emax}}$ and $\mathrm{P}_{\text {Imax }}$ followed a complex pattern. When analyzing the relationship between $\mathrm{P}_{\mathrm{Emax}} / \mathrm{P}_{\mathrm{Imax}}$ and age (Fig. 2, bottom panels), it was found that, in healthy subjects, the ratio was invariant with age, whereas, in NMDs, again, it followed a more complex pattern. In older subjects, variability of $\mathrm{P}_{\text {Emax }} / \mathrm{P}_{\text {Imax }}$ was greater than in younger subjects. When the same relationship was analyzed in the different NMDs (Fig. 3), we found that only in MD, but not in MG and ALS, a significant progressive increase of $\mathrm{P}_{\mathrm{Emax}} / \mathrm{P}_{\text {Imax }}$ ratio with age was present (MD: $\mathrm{r}^{2}=0.27, P=.008$; MG: $\mathrm{r}^{2}=0.07, P=.18$; ALS: $\left.\mathrm{r}^{2}=0.18, P=.08\right)$.

\section{Discussion}

NMDs are progressive conditions leading to respiratory failure and severe disability. Therefore, a close clinical follow-up and a systematic evaluation of respiratory muscles and lung function are essential. ${ }^{16}$ In the present study, we introduce the $\mathrm{P}_{\mathrm{Emax}} / \mathrm{P}_{\text {Imax }}$ (ratio between both absolute and percent of predicted values) as a simple way to describe the relative impairment of inspiratory versus expiratory muscles in NMDs. The main findings were that $\mathrm{P}_{\text {Emax }} / \mathrm{P}_{\text {Imax }}$ is lower than normal in $\mathrm{MD}$, higher than normal in MG, and highly variable in ALS. This means that, in $\mathrm{MD}$, expiratory muscles are relatively more impaired than inspiratory muscles, vice versa in MG, whereas, in ALS, a more complex and variable situation is present.

Our results regarding subjects with MD are in agreement with those of Veale et al, ${ }^{6}$ who compared respiratory pattern during sleep and wakefulness in healthy subjects and subjects with MD and other NMDs. These authors found that, despite a similar degree of respiratory muscle weakness in the 2 groups of subjects, those with MD showed lower $\mathrm{P}_{\mathrm{Emax}}$, suggesting more impairment of expiratory muscles, presumably abdominal ones.

Regarding the subjects from our MG group, the relationship $\mathrm{P}_{\mathrm{Emax}} / \mathrm{P}_{\text {Imax }}$ was the highest compared with the other considered NMDs. In our MG group, 17 subjects (55\%) showed $\mathrm{P}_{\text {Emax }}$ values similar to those of healthy 

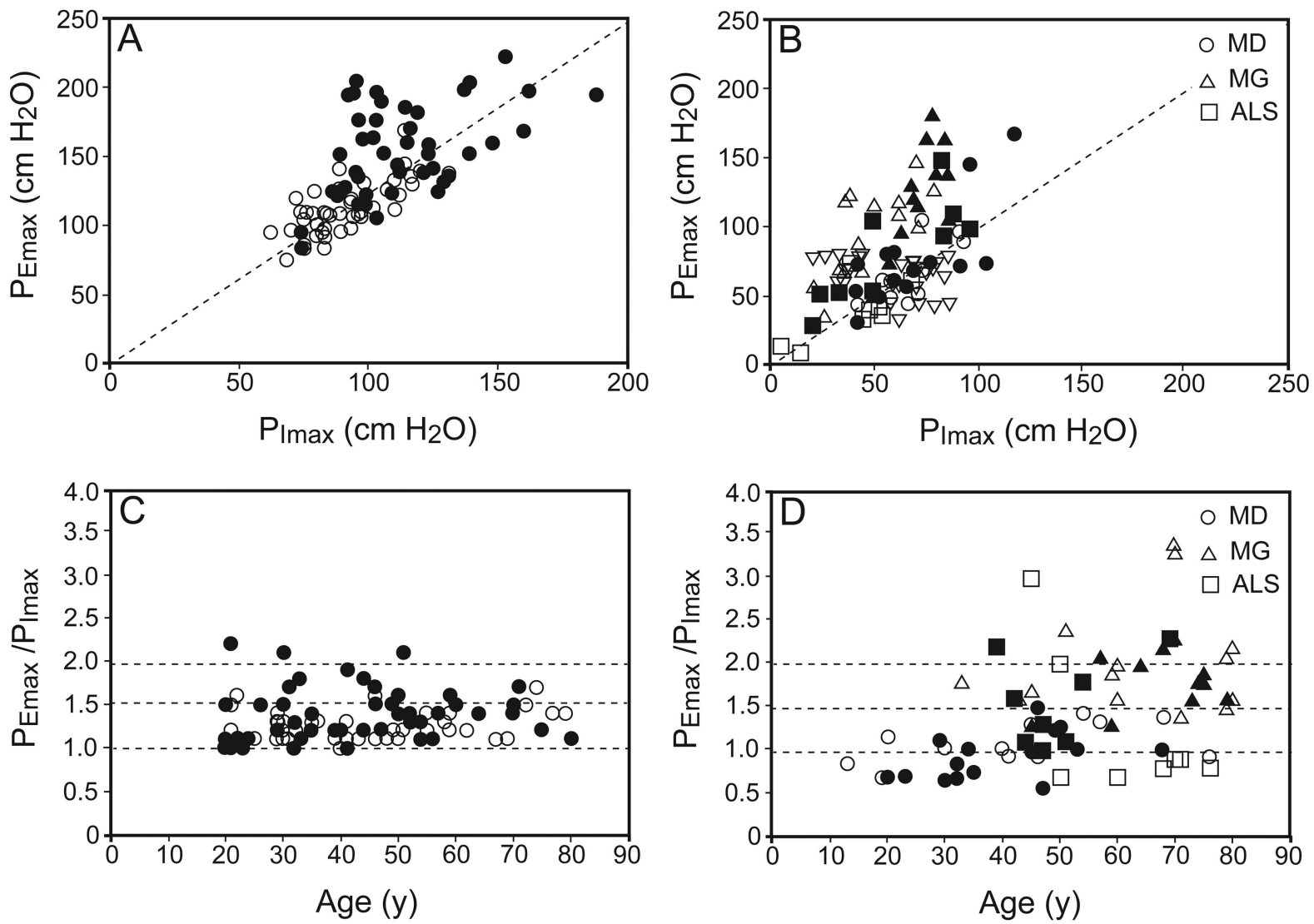

Fig. 2. Relationship between $P_{E \max }$ and $P_{\text {Imax }}$ for healthy individuals (A) and subjects with neuromuscular diseases (NMDs) among the pathologies (B). Also shown is the $P_{E \max } / P_{I m a x}$ ratio relationship to age in healthy subjects (C) and subjects with NMDs (D). Open shapes are females, and closed shapes are males. ALS = amyotrophic lateral sclerosis; MG = myasthenia gravis; MD = myotonic dystrophy. In C, the horizontal lines represent the majority concentration of healthy subjects $(1.5 \pm 0.5)$ They are repeated in $D$ to compare the distribution of NMD subjects.
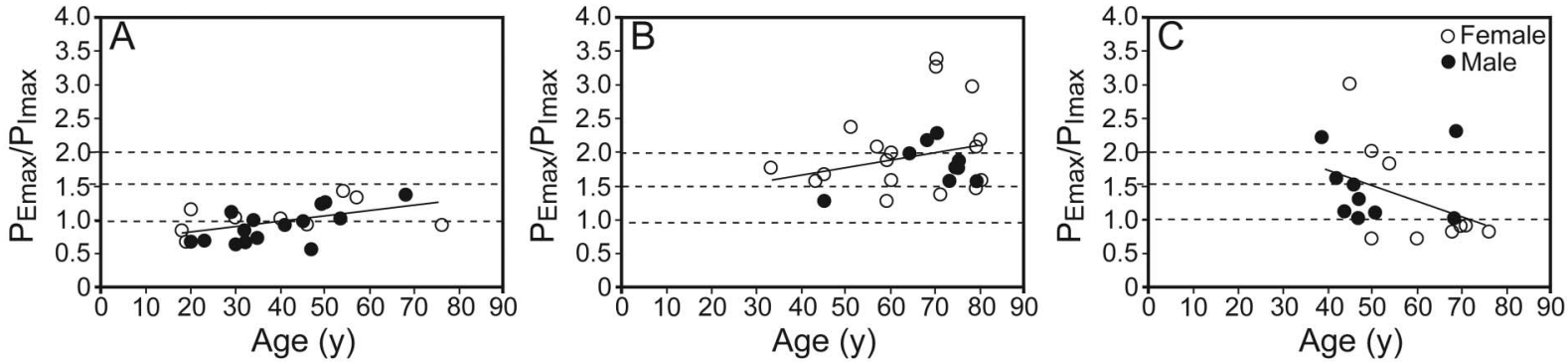

Fig. 3. $P_{E \max }$ minus $P_{\operatorname{Imax}}$ versus age for myotonic dystrophy $(A)$, myasthenia gravis $(B)$, and amyotrophic lateral sclerosis $(C)$. Single linear regression was used to identify a $P_{E \max }$ minus $P_{I \max }$ versus age pattern $(p<.001)$. Open shapes are females, and closed shapes are males. Horizontal lines indicate the majority concentration in healthy subjects $(1.5 \pm 0.5)$ as a comparison.

subjects and 27 subjects $(100 \%)$ lower $\mathrm{P}_{\text {Imax }}$ values, so determining high values of $\mathrm{P}_{\text {Emax }} / \mathrm{P}_{\text {Imax }}$. Our results are apparently in partial disagreement with those of Weiner et $\mathrm{al}^{17}$ and Keenan et al, ${ }^{18}$ who studied subjects with severe and moderate generalized MG, and found that both $\mathrm{P}_{\mathrm{Emax}}$ and $\mathrm{P}_{\text {Imax }}$ were lower than normal. However, our group of
MG subjects included those with only mild/moderate, and not severe, generalized MG.

Our ALS subjects had, on average, a $\mathrm{P}_{\text {Emax }} / \mathrm{P}_{\text {Imax }}$ ratio similar to healthy subjects. The variability, however, was extremely high, presumably due to disease severity and/or disease progression. Several previous studies tried to es- 
tablish a relationship between the degree of respiratory muscle weakness and distribution of weakness (diaphragmatic vs overall muscle weakness) and lung volumes. Qureshi et $\mathrm{al}^{5}$ investigated risk factors and predictors of disease progression in 95 subjects with ALS and 106 healthy subjects over 12 months. They observed normal total lung capacity, elevated residual volume, reduced FVC, and diminished respiratory muscle strength (both inspiratory and expiratory), with a greater decline in $\mathrm{P}_{\mathrm{Emax}}$ than in $\mathrm{P}_{\text {Imax }}$. The study showed that a marked reduction in $\mathrm{P}_{\mathrm{Emax}}$ determines increased residual volume, and, in more general terms, a lower efficiency in the use of expiratory muscles. Park et $\mathrm{al}^{4}$ studied 45 ALS subjects, and also found that both $\mathrm{P}_{\mathrm{Emax}}$ and $\mathrm{P}_{\text {Imax }}$ were markedly decreased, in addition to a lower $\mathrm{P}_{\mathrm{Emax}}(\%$ predicted $) / \mathrm{P}_{\text {Imax }}(\%$ predicted $)$ ratio (equal to 0.89 ), suggesting more impairment in expiratory than inspiratory muscles. These results are in agreement with ours.

A potential limitation of our study is the small sample size of the NMD groups because of the difficulty in the number of subjects available to be part of the study. Furthermore, the different stages/progression of diseases and heterogeneity of sample size, in terms of gender, age, and BMI, as well as including some subjects receiving nocturnal noninvasive mechanical ventilation, are also limitations. However, the main aim of the present study was not to investigate the effect of specific parameters on respiratory muscle strength, but to characterize NMDs in terms of relative impairment of inspiratory and expiratory muscles.

The results add new perspectives in terms of respiratory muscle assessment in subjects with NMDs. The use of $\mathrm{P}_{\text {Emax }} / \mathrm{P}_{\text {Imax }}$ ratio, either absolute or percent of predicted, is a simple way to assess the relative impairment of inspiratory versus expiratory muscles and therefore to plan and adjust the treatment. Future studies are needed to further corroborate our findings.

\section{Conclusions}

Healthy individuals and subjects with NMDs showed higher $\mathrm{P}_{\text {Emax }}$ in comparison to $\mathrm{P}_{\text {Imax }}$ regarding the $\mathrm{P}_{\text {Emax }} / \mathrm{P}_{\text {Imax }}$ ratio. Based on the ratio, it is possible to state that NMDs show different patterns of respiratory muscle strength loss. In our study, we found that subjects with MD show a predominant expiratory muscle weakness, and subjects with MG show a predominant inspiratory muscle weakness, whereas, in subjects with ALS, a more complex pattern, presumably dependent on severity/progression of the disease, is present. $\mathrm{P}_{\mathrm{Emax}} / \mathrm{P}_{\mathrm{Imax}}$ ratio is a useful parameter to assess the impairment of respiratory muscles in a patient and to customize rehabilitation and treatment.

\section{REFERENCES}

1. Racca F, Del Sorbo L, Mongini T, Vianello A, Ranieri VM. Respiratory management of acute respiratory failure in neuromuscular diseases. Minerva Anestesiol 2010;76(1):51-62.

2. Black LF, Hyatt RE. Maximal respiratory pressures: normal values and relationship to age and sex. Am Rev Respir Dis 1969;(5):696702 .

3. Society ATSER. ATS/ERS statement on respiratory muscle testing. Am J Respir Crit Care Med 2002;15(166):106.

4. Park JH, Kang SW, Lee SC, Choi WA, Kim DH. How respiratory muscle strength correlates with cough capacity in patients with respiratory muscle weakness. Yonsei Med J 2010;51(3):7.

5. Qureshi MM, Hayden D, Urbinelli L, Ferrante K, Newhall K, Myers $\mathrm{D}$, et al. Analysis of factors that modify susceptibility and rate of progression in amyotrophic lateral sclerosis (ALS). Amyotroph Lateral Scler 2006;7(3):173-182.

6. Veale D, Cooper BG, Gilmartin JJ, Walls TJ, Griffith CJ, Gibson GJ. Breathing pattern awake and asleep in patients with myotonic dystrophy. Eur Respir J 1995;8(5):815-8.

7. Ambrosino N, Carpenè N, Gherardi M. Chronic respiratory care for neuromuscular diseases in adults. Eur Respir J 2009;34(2):444-451.

8. Misuri G, Lanini B, Gigliotti F, Iandelli I, Pizzi A, Bertolini MG, Scano G. Mechanism of $\mathrm{CO}(2)$ retention in patients with neuromuscular disease. Chest 2000;117(2):447-453.

9. D’Angelo MG, Romei M, Lo Mauro A, Marchi E, Gandossini S, Bonato S, et al. Respiratory pattern in an adult population of dystrophic patients. J Neurol Sci 306(1-2):54-61, 2011.

10. Troosters T, Gosselink R, Decramer M. Respiratory muscle assessment. Eur Respir Mon 2005;31:14.

11. Association WM. Declaration of Helsinki: ethical principles for research involving human subjects. J Postgrad Med. 2002;158.

12. Sociedade Brasileira de Pneumologia e Tisiologia. Diretrizes para testes de função pulmonar. J Pneumol. 2002;28(3):237. Article in Portuguese.

13. Pereira CAC, Sato T, Rodrigues SC. Novos valores de referência para espirometria forçada em adultos de raça branca. J Bras Pneumol 2007;33:9. Article in Portuguese.

14. Neder JA, Andreoni S, Lerario MC, Nery LE. Reference values for lung function tests. II. Maximal respiratory pressures and voluntary ventilation. Braz J Med Biol Res 1999;32(6):719-727.

15. World Health Organization. Global database on body mass index (BMI). http://www.who.int/nutrition/databases/bmi/en. Accessed July 30, 2014.

16. Simonds AK. Recent advances in respiratory care for neuromuscular disease. Chest 2006;130(6):1879-1886.

17. Weiner P, Gross D, Meiner Z, Ganem R, Weiner M, Zamir D, Rabner M. Respiratory muscle training in patients with moderate to severe myasthenia gravis. Can J Neurol Sci 1998;25(3):236-241.

18. Keenan SP, Alexander D, Road JD, Ryan CF, Oger J, Wilcox PG. Ventilatory muscle strength and endurance in myasthenia gravis. Eur Respir J 1995;8(7):1130-1135. 